\title{
Imaging Features of Juvenile Xanthogranuloma of the Pediatric Head and Neck
}

\author{
DD.T. Ginat, S.O. Vargas, V.M. Silvera, M.S. Volk, B.A. Degar, and (1)C.D. Robson
}

\begin{abstract}
BACKGROUND AND PURPOSE: Juvenile xanthogranuloma is a non-Langerhans cell histiocytosis primarily affecting children. The purpose of this study was to characterize the imaging features of histologically confirmed pediatric head and neck juvenile xanthogranuloma.
\end{abstract}

MATERIALS AND METHODS: A retrospective review was performed of medical records and imaging of histologically confirmed head and neck juvenile xanthogranuloma.

RESULTS: Ten patients (6 girls, 4 boys) 1 month to 12 years of age were imaged with ultrasound only $(n=1)$, CT only $(n=2)$, CT and ultrasound $(n=1)$, MR imaging only $(n=3)$, or MR imaging and CT $(n=3)$. Masses were solitary in 9 patients and multiple in 1. Solitary masses were located in the external auditory canal, infra-auricular region, infratemporal fossa with intracranial extension, frontal scalp, and subperiosteal space eroding the calvaria and along the dura. One patient with disseminated disease had scalp-, calvarial-, and dural-based masses. Clinical presentation included a mass or alteration in function. On sonography, juvenile xanthogranuloma appeared hypoechoic. On contrast-enhanced CT, masses appeared homogeneous and isoattenuating with muscle and sometimes eroded bone. On MR imaging, compared with the cerebral cortex, the masses appeared hyper- or isointense on $\mathrm{Tl}$ and hypo- or isointense on $\mathrm{T} 2$, had decreased diffusivity, and enhanced homogeneously. Juvenile xanthogranuloma was not included in the differential diagnosis in any case.

CONCLUSIONS: Head and neck juvenile xanthogranuloma has varied manifestations. Mild hyperintensity on T1, hypointensity on T2 compared with the cerebral cortex, decreased diffusivity, and homogeneous enhancement are characteristic. Awareness of these features should prompt radiologists to include juvenile xanthogranuloma in the differential diagnosis of pediatric head and neck masses.

ABBREVIATIONS: $\mathrm{HN}=$ head and neck; JXG = juvenile xanthogranuloma; $\mathrm{LCH}=$ Langerhans cell histiocytosis; US = ultrasound

J uvenile xanthogranuloma (JXG) is a non-Langerhans cell histiocytosis that typically presents as a well-circumscribed nodule or mass, containing attenuated infiltrates of histiocytes and a variable number of admixed multinucleate Touton giant cells and

Received November 1, 2014; accepted after revision November 10, 2015 From the Departments of Radiology (D.T.G., V.M.S., C.D.R.), Pathology (S.O.V.), Otolaryngology (M.S.V.), and Pediatric Oncology (B.A.D.), Boston Children's Hospital, Boston, Massachusetts; Department of Pediatric Oncology (B.A.D.), Dana-Farber Cancer Institute, Boston, Massachusetts; and Harvard Medical School (S.O.V., V.M.S., M.S.V., B.A.D., C.D.R.), Boston, Massachusetts.

Current affiliation for D.T.G.: Department of Radiology, University of Chicago Medical Center, Chicago, Illinois.

Previously presented as a poster at: Annual Meeting of the American Society of Head and Neck Radiology, September 25-29, 2013; Milwaukee, Wisconsin.

Please address correspondence to Caroline D. Robson, MB, ChB, Department of Radiology, Boston Children's Hospital, 300 Longwood Ave, Boston, MA 02115;

e-mail: caroline.robson@childrens.harvard.edu

http://dx.doi.org/10.3174/ajnr.A4644 inflammatory cells. The cell of origin in JXG is debated; the cells have immunohistochemical features of both macrophages and dendritic cells. ${ }^{1}$ Approximately $20 \%$ of JXGs are noted at birth; $70 \%$, in the first year of life; and only $10 \%$, in adulthood. Localized dermal involvement is the most common presentation; twothirds of the lesions are solitary. ${ }^{2}$ Extracutaneous involvement is less common, with approximately $50 \%$ of lesions located within the head and neck (HN) region. $^{2}$ Extracutaneous HN JXG has been reported in locations such as the tympanic membrane, nasal cavity, tongue, orbit and paranasal sinus, subglottis, cervical spine, skull base including the temporal bone, intracranial compartment, and $\mathrm{HN}$ muscles. ${ }^{2-21}$

Cutaneous JXG typically presents as a solitary macule or papule with a flesh-colored, erythematous, or yellowish hue. ${ }^{2}$ In such cases, radiographic imaging is not indicated. In extracutaneous sites, JXG is more difficult to diagnose and imaging can be misleading 


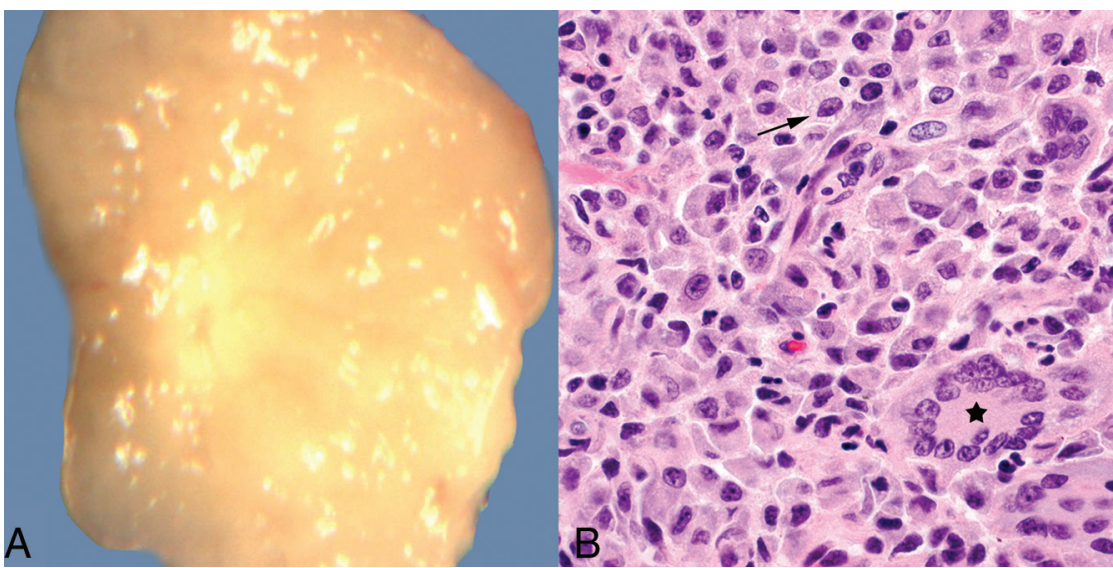

FIG 1. $A$, Grossly, juvenile xanthogranulomas are typically yellowish, due to their high lipid content. $B$, Hematoxylin-eosin stain, original magnification $\times 600$. Microscopically, abundant variably lipidized histiocytes are present (arrow), usually with admixed Touton giant cells (star) and scattered inflammatory cells (not shown on this image).

because an infiltrative appearance may mimic malignancy. ${ }^{2,22}$ Previous reports detailing the radiographic features of JXG are limited to case reports and several small series or to a limited description of imaging within the context of a clinicopathologic report. ${ }^{2-21}$

The purpose of this study was to provide detailed characterization of the ultrasound (US), CT, and MR imaging features of JXG in the HN region.

\section{MATERIALS AND METHODS}

Boston Children's Hospital institutional review board approval was obtained for a retrospective review of pathologically confirmed pediatric cases of JXG. The pathology data base at Boston Children's Hospital was searched for all reports containing the text "xanthog" in patients younger than 19 years of age from December 1997 to December 2013. Cases were included only if the incisional or excisional biopsy met histologic criteria for JXG. The site of each biopsy was recorded. Patients with biopsies showing JXG involving the HN were studied further by review of their pathology and radiology records. Pathology was reviewed by a pediatric pathologist. Radiology examinations were reviewed by a pediatric neuroradiologist with approximately 20 years of experience and a neuroradiology fellow. For patients who were imaged with sonography, CT, and/or MR imaging, original images were reviewed in detail. The maximum lesion diameter on the presenting imaging examination was recorded. The attenuation of the lesions was compared with that of muscle by visual inspection on available noncontrast and postcontrast CT images. MR imaging technical parameters were as follows: T1-weighted images: TR/ TE, 427-667/10-25 ms; NEX, 2; matrix, 205-256 × 256-512; FOV, 15-22 × 18-27 cm; T2-weighted sequences: TR/TE, 26935800/86-120 ms; NEX, 1-2; matrix, 179-256 × 320-512; FOV, $15-20 \times 18-25 \mathrm{~cm}$; fast spin-echo inversion recovery sequences: TR/TE, 4000/45 ms; NEX, 2; matrix, $256 \times 512$; FOV, $22 \times 28 \mathrm{~cm}$; and diffusion-weighted sequences: TR/TE, 8300/93 ms; NEX, 1; matrix, $128 \times 128$; FOV, $18-26 \times 22-32 \mathrm{~cm}$; b-value, 1000). Contrast-enhanced images of extracranial lesions were obtained with similar parameters with fat-suppression. Lesion signal intensity on T1-weighted and fast spin-echo T2-weighted or fast spinecho inversion recovery sequences was designated as hypointense, isointense, or hyperintense with respect to the signal intensity of the cerebral cortex, based on visual inspection. The presence of enhancement on postcontrast T1weighted sequences within the lesions was characterized as homogeneous versus heterogeneous. ADC maps were generated from diffusion-weighted images, and whole-lesion average $\mathrm{ADC}$ measurements were obtained by using a freehand ROI. The differential diagnosis provided on the original radiology reports was assessed for the 9 patients for whom the histopathologic diagnosis of JXG was not known at the time of imaging.

\section{RESULTS}

During a 16-year period, there were 114 children with a histologic diagnosis of JXG. Lesions involved the skin in 107 (94\%) of these patients. Multiple lesions were present in 8 patients. Imaging was performed in 14 of $114(12 \%)$ patients. Imaged lesions involved the skin and subcutaneous tissues (back, chest, neck, scalp, and groin), abdominal wall rectus sheath, paraspinal muscles, liver, neck, skull, and external auditory meatus. The HN was involved in 67 of 114 (59\%) patients. Sites of cutaneous HN involvement included the forehead, cheek, nose, chin, ear, eyelid, lip, neck, and scalp. Review of pathologic features in all cases revealed diagnostic features of JXG (Fig 1). The features included an infiltrate of variably xanthomatized mononuclear histiocyte-like cells. Touton giant cells were seen in all except 1 case, and eosinophils and lymphocytes were seen in most cases.

Ten patients had imaging of HN lesions. The 6 female and 4 male patients ranged in age from 1 month to 12 years at the time of imaging, with 8 children younger than 1 year of age. Their clinical presentations and initial radiologic diagnoses based on the imaging findings are summarized in Table 1 . US only was performed in 1 patient; US and CT, in 1 patient; CT only, in 2 patients; MR imaging only, in 3; and both MR imaging and CT, in 3 . Imaging characteristics are summarized in Table 2. Lesions were solitary in 9 children and multiple in 1 patient who had disseminated disease. Maximum diameters of the lesions in the $10 \mathrm{pa}-$ tients ranged from 2 to $60 \mathrm{~mm}$.

Doppler US examinations performed for evaluation of each of the superficial lesions, one adjacent to the coronal suture and the other in the infra-auricular region (Fig 2), revealed sharply defined, ovoid, slightly heterogeneous, hypoechoic masses without demonstrable internal blood flow.

On contrast-enhanced CT, the lesions appeared as homogeneous, solid soft-tissue masses without calcifications and isoattenuating compared with muscle (Fig 2). Bony erosion was present in 3 of 5 children (Figs 3 and 4). CT in 1 patient with a right parietal subperiosteal mass showed an irregular and somewhat aggressive-appearing erosion of the calvarial outer table with a peripheral periosteal reaction (Fig 4). CT in another patient showed mild, smooth, benign-appearing thinning of the frontal bone outer table in the midline above the nasofrontal suture. CT 
Table 1: Patient age and sex, clinical presentation, lesion location, and radiographic diagnosis

\begin{tabular}{|c|c|c|c|c|}
\hline Case & Age, Sex & Clinical Presentation & Location & Radiographic Diagnosis \\
\hline 1 & $10 \mathrm{yr}, \mathrm{F}$ & $\begin{array}{l}\text { Mass and bloody } \\
\text { otorrhea for } 10 \text { days }\end{array}$ & External auditory canal, polypoid mass & Polyp \\
\hline 2 & $4 \mathrm{mo}, \mathrm{M}$ & $\begin{array}{l}\text { Mass and bloody } \\
\text { discharge for } 1 \text { month }\end{array}$ & $\begin{array}{l}\text { External auditory canal, subcutaneous } \\
\text { tissues }\end{array}$ & $\begin{array}{l}\text { Sebaceous cyst, dermoid or branchial } \\
\text { cleft cyst }\end{array}$ \\
\hline 3 & $3 \mathrm{mo}, \mathrm{M}$ & $\begin{array}{l}\text { Reddish-blue nodule } \\
\text { for } 2 \text { days }\end{array}$ & $\begin{array}{l}\text { Infra-auricular, subcutaneous, and } \\
\text { cutaneous }\end{array}$ & $\begin{array}{l}\text { Lymph node, pilomatrixoma, nontuberculous } \\
\text { mycobacterial infection }\end{array}$ \\
\hline 4 & $1 \mathrm{mo}, \mathrm{M}$ & $\begin{array}{l}\text { Facial weakness, } \\
\text { otorrhea for } 1 \text { month }\end{array}$ & $\begin{array}{l}\text { Infratemporal fossa, middle ear space, } \\
\text { bony erosion, intracranial, temporal } \\
\text { lobe edema }\end{array}$ & $\mathrm{LCH}$, neuroblastoma \\
\hline 5 & $7 \mathrm{mo}, \mathrm{F}$ & Scalp mass for 2 weeks & $\begin{array}{l}\text { Subperiosteal with outer table } \\
\text { erosion, parietal bone }\end{array}$ & $\begin{array}{l}\text { Neuroblastoma metastasis, LCH, fibromatosis, } \\
\text { other malignant tumor }\end{array}$ \\
\hline 6 & $4 \mathrm{mo}, \mathrm{F}$ & $\begin{array}{l}\text { Enlarging scalp mass for } \\
\quad 6 \text { weeks }\end{array}$ & $\begin{array}{l}\text { Cutaneous edema, subcutaneous } \\
\text { scalp mass over coronal suture }\end{array}$ & Dermoid \\
\hline 7 & $1 \mathrm{mo}, \mathrm{F}$ & Mass over nose since birth & $\begin{array}{l}\text { Subcutaneous tissue, midline } \\
\text { nasofrontal }\end{array}$ & Neuroglial heterotopia \\
\hline 8 & $10 \mathrm{mo}, \mathrm{F}$ & $\begin{array}{l}\text { Enlarging mass over } \\
\text { nose for } 3 \text { weeks }\end{array}$ & $\begin{array}{l}\text { Subperiosteal with outer table } \\
\text { erosion, midline frontal }\end{array}$ & $\begin{array}{l}\mathrm{LCH} \text {, metastasis such as neuroblastoma, } \\
\text { other malignant tumor }\end{array}$ \\
\hline 9 & $12 \mathrm{yr}, \mathrm{F}$ & $\begin{array}{l}\text { Tremor for } 6 \text { months, } \\
\text { recent seizure }\end{array}$ & $\begin{array}{l}\text { Intracranial, extra-axial; frontal lobe } \\
\text { edema }\end{array}$ & Tumor not otherwise specified \\
\hline 10 & $9 \mathrm{mo}, \mathrm{M}$ & $\begin{array}{l}\text { Multiple skin lesions } \\
\text { since birth, occipital } \\
\text { lesion for } 4 \text { weeks }\end{array}$ & $\begin{array}{l}\text { Innumerable scalp lesions; occipital } \\
\text { calvarial, epidural; intracranial } \\
\text { parietal dural-based }\end{array}$ & $\begin{array}{l}\text { Referred for imaging with known diagnosis } \\
\text { of JXG }\end{array}$ \\
\hline
\end{tabular}

Table 2: Lesion characteristics on CT and MR imaging

\begin{tabular}{|c|c|c|c|c|c|c|c|c|c|}
\hline Case & $\begin{array}{l}\text { Size } \\
(\mathrm{mm})\end{array}$ & US & $\begin{array}{l}\text { CT Attenuation }{ }^{\mathrm{a}} \\
\text { without Contrast }\end{array}$ & $\begin{array}{l}\text { CT Attenuation }^{\mathrm{a}} \\
\text { with Contrast }\end{array}$ & $\begin{array}{l}\text { Bony } \\
\text { Erosion }\end{array}$ & $\begin{array}{l}\text { Relative Signal } \\
\text { Intensity on } \mathrm{T}^{\mathrm{b}}\end{array}$ & $\begin{array}{l}\text { Relative Signal } \\
\text { Intensity on } \mathrm{T}^{\mathrm{b}} \\
\end{array}$ & $\begin{array}{l}\text { Enhancement } \\
\text { Postgadolinium }\end{array}$ & $\begin{array}{c}\text { ADC } \\
\left(\times 10^{-3} \mathrm{~mm}^{2} / \mathrm{s}\right)\end{array}$ \\
\hline 1 & 6 & NA & NA & Iso & - & NA & NA & NA & NA \\
\hline 2 & 5 & NA & NA & Iso & - & NA & NA & NA & NA \\
\hline 3 & 10 & Hypoechoic & NA & Iso & - & NA & NA & NA & NA \\
\hline 4 & 43 & NA & Iso & NA & + & Hyper & Нyро & Homogeneous & 0.739 \\
\hline 5 & 34 & NA & Iso & NA & + & Hyper & Нyро & Homogeneous & NA \\
\hline 6 & 15 & Hypoechoic & NA & NA & NA & NA & NA & NA & NA \\
\hline 7 & 27 & NA & NA & Iso & + & Hyper & Нуро & Homogeneous & 0.534 \\
\hline 8 & 4 & NA & NA & NA & + & Iso & Нyро & Homogeneous & 0.596 \\
\hline 9 & 8 & NA & NA & NA & - & Iso & Iso & Homogeneous & NA \\
\hline 10 & $2-17$ & NA & NA & NA & + & Iso & Iso & Homogeneous & 0.777 (largest) \\
\hline
\end{tabular}

Note:-Iso indicates isoattenuating; Hyper, hyperintense; Hypo, hypointense; -, absent; +, present; NA, not available.

${ }^{a}$ Compared with muscle.

${ }^{\mathrm{b}}$ Compared with gray matter.

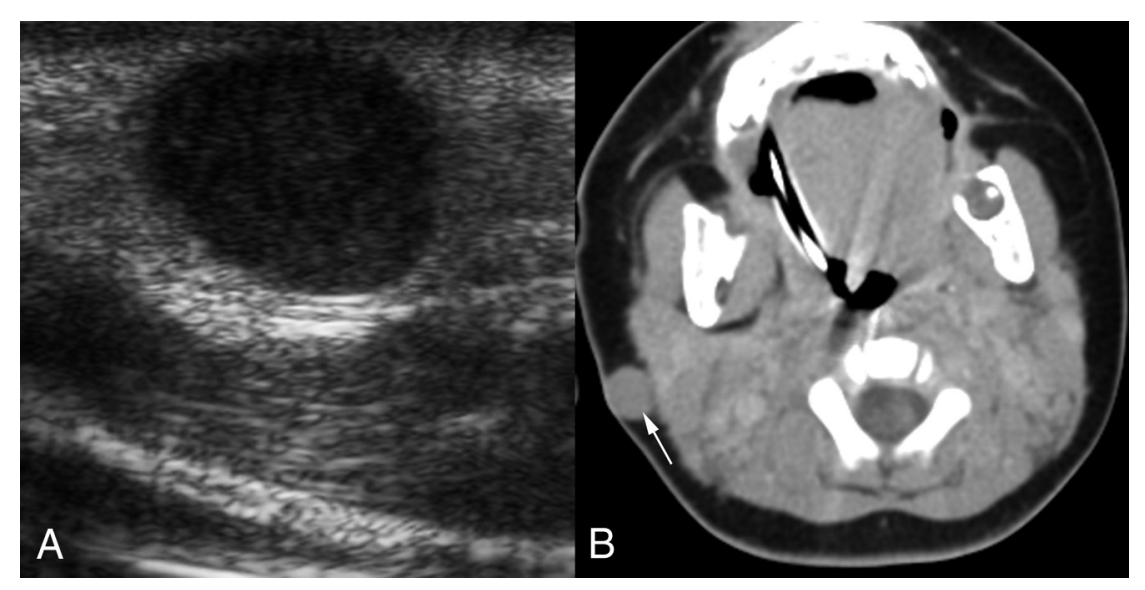

FIG 2. A 3-month-old boy with a reddish-blue infra-auricular nodule that had been noticed for 2 days (patient 3). A, Transverse sonographic image reveals a hypoechoic solid mass. The mass was mistaken for adenopathy. $B$, Axial contrast-enhanced CT image shows a sharply circumscribed subcutaneous mass (arrow) that also involves the skin. The mass is isoattenuating with muscle and has no distinguishing characteristics other than its location. The lack of calcification is unusual for pilomatrixoma, which is the most common tumor in this location in children. The lack of necrosis or parotid space adenopathy is atypical for nontuberculous mycobacterial infection, which is the most common infection in this location. in a third patient showed lytic destruction of the temporal bone affecting the floor of the middle ear space, the tegmen tympani, and the lateral retroauricular mastoid cortex. There was also erosion of the ossicles and otic capsule region of the petrous bone (Fig 3). Bony erosion was not identified in 3 of 6 children. All of these children had small, nonspecific, enhancing soft-tissue masses projecting into the external auditory canal or involving the skin and subcutaneous tissues beneath the ear (Fig 2).

As suggested by the range of technical parameters, the MR imaging technique has evolved considerably during the study period, with a more recent trend toward imaging on 3T systems using multichannel phased array coils with an FOV optimized for the ROI and higher resolution imaging. Neverthe- 


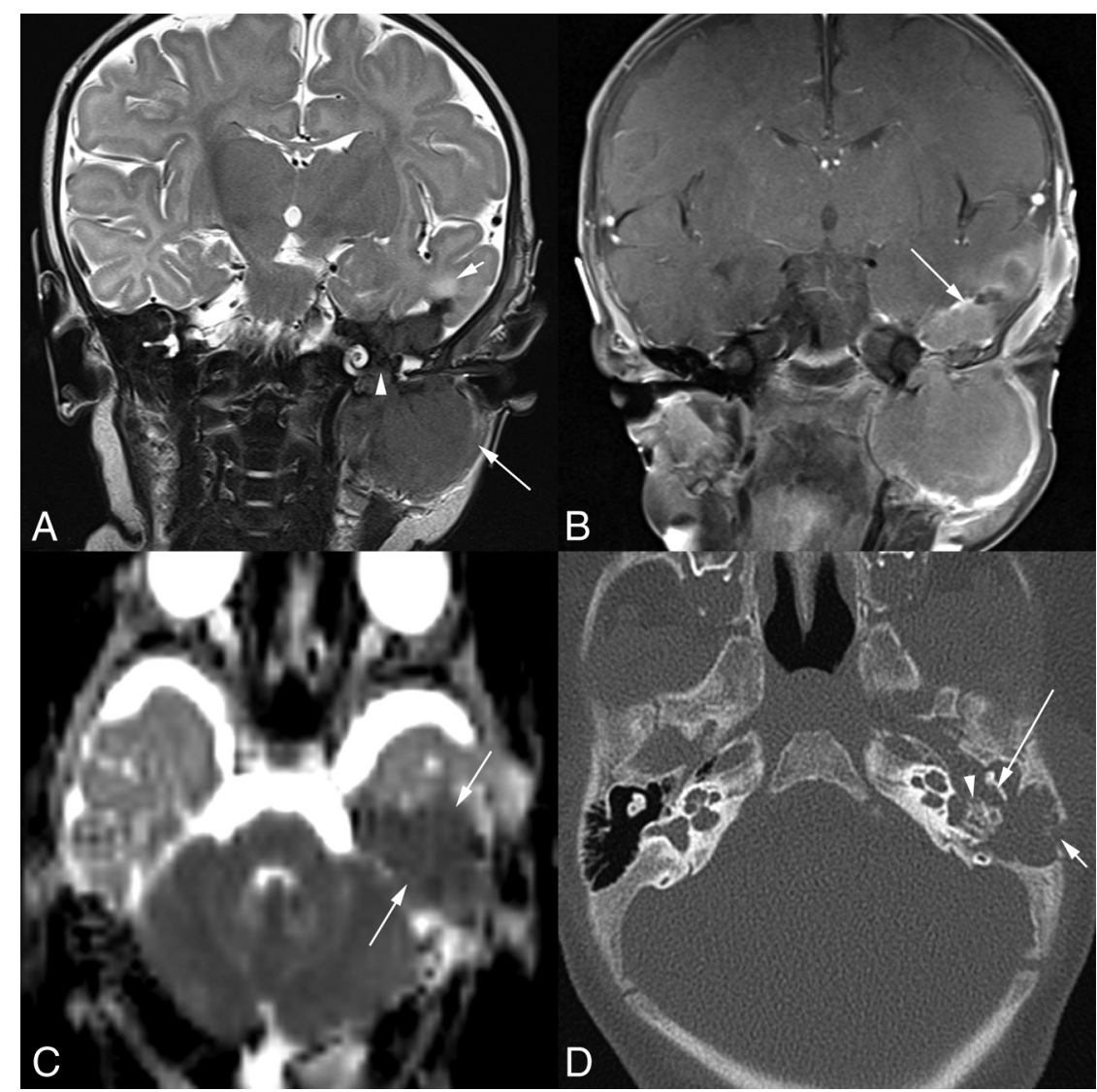

FIG 3. A 1-month-old boy with a 1-month history of left facial weakness and otorrhea (patient 4). $A$, Coronal T2-weighted MR image shows a mass that is hypointense compared with the cortex. Tumor involves the infratemporal fossa (long arrow), erodes the skull base and tegmen tympani, and involves the middle ear space (arrowhead) and epidural space in the middle cranial fossa. There is edema of the adjacent temporal lobe (short arrow). Scalp swelling is due to recent surgical debulking of the intracranial component at another institution. $B$, Coronal contrastenhanced, fat-suppressed T1-weighted MR imaging shows the homogeneously enhancing mass extending into the middle ear space and the epidural space (arrow). C, On this axial DWI ADC image, the lesion (arrows) demonstrates decreased diffusivity. Axial CT image $(D)$ shows lytic destruction of the mastoid temporal bone retroauricular cortex (short arrow). Tumor extends into the left middle ear space with erosion of the short process of the incus (long arrow) along its medial aspect and erosion of the otic capsule bone around the oval window and lateral semicircular canal (arrowhead).

less, on T2-weighted MR images, the JXG ranged from hypointense ( 3 of 6 patients) to isointense ( 3 of 6 patients) relative to gray matter (Figs 3-5), while on T1-weighted sequences before administration of contrast, the lesions ranged from isointense (3 of 6 patients) to hyperintense ( 3 of 6 patients) relative to gray matter (Figs 4 and 5). Diffusion-weighted imaging was available in 4 cases, and the lesions demonstrated decreased diffusivity (Figs 3 and 5), appearing hypointense relative to the cortex on ADC maps, with average $\mathrm{ADC}$ values of the lesions ranging from 0.53 to $0.78 \times 10^{-3} \mathrm{~s} / \mathrm{mm}^{2}$. Enhancement on postcontrast T1-weighted MR imaging was homogeneous in all patients (Figs 3-7).

Two patients had extra-axial lesions associated with edema in the adjacent brain parenchyma with seizures in one of these children (Figs 3 and 6). The other child presented a few weeks after birth with left facial weakness, and imaging revealed temporal bone erosion, as detailed earlier, with progressive enlargement in the soft-tissue components extending inferiorly into the infratemporal fossa and superiorly into the middle cranial fossa on serial imaging (Fig 3). One patient had disseminated disease with innumerable cutaneous and subcutaneous lesions; a calvarial mass; and lobulated, plaquelike dural-based lesions (Fig 7). This patient also had abdominal visceral involvement.

A diagnosis of JXG before head and neck imaging was known in only 1 patient who had cutaneous lesions and disseminated disease. For the remaining 9 patients, the radiologic differential diagnosis provided for the tumor varied depending on the location of the tumor (Table 1). Proposed differential diagnoses included Langerhans cell histiocytosis $(\mathrm{LCH})$ or neuroblastoma (masses with bony erosion), neuroglial heterotopia (midline nasofrontal mass), granulomatous inflammation, lymph node or nonmineralized pilomatrixoma (subcutaneous infra-auricular lesion), epidermoid or dermoid (lesion over a coronal suture and external auditory canal lesion), and first branchial cleft cyst or polyp (external auditory canal lesion). Most interesting, JXG was not included in the initial radiologic differential diagnosis for any of these 9 patients.

\section{DISCUSSION}

Our study confirmed that the $\mathrm{HN}$ is a favored location for both cutaneous and extracutaneous JXG; the latter included the calvaria, midline nasofrontal region, periauricular region, and temporal bone. Intracranial disease in our series manifested as a dural-based mass or masses. Multifocal disease is rarely encountered. A small but important proportion of all pediatric JXG cases (12\%) of this classic pediatric disease undergo preoperative imaging. Our study demonstrated the range of US, CT, and MR imaging findings in primarily extracutaneous JXG of the pediatric HN. We also showed that while only a small fraction of all pediatric JXGs were imaged, this entity was seldom included by the radiologist in the differential diagnosis of $\mathrm{HN}$ masses.

Our findings, based on the evaluation of a very limited number of patients, suggest that on US, the presence of a solid, sharply circumscribed, superficial, nonmineralized mass should prompt consideration of JXG in the differential diagnosis. Hypoechoic and relatively avascular sonographic characteristics help distinguish JXG from lymph nodes. Bone erosion associated with JXG was not an uncommon finding in this series and could be depicted on both CT and MR imaging. Indeed, the presence of bone involvement has been described as a feature of JXG, but not of adult xanthogranuloma. ${ }^{17} \mathrm{Tu}$ mors that demonstrated punched-out lytic destruction resembled LCH most closely. However, 1 tumor demonstrated irreg- 
ular calvarial destruction simulating a higher grade primary or metastatic tumor.

On CT, JXGs have been described as masses of soft-tissue attenuation with central areas of hypoattenuation in the muscles, lungs, kidney, liver, and adrenal glands and as small hypoattenuating nodules in the spleen. ${ }^{23}$ In this series, the cases for which contrast-enhanced CT was performed were homogeneously isoattenuating compared with muscle, without central areas of

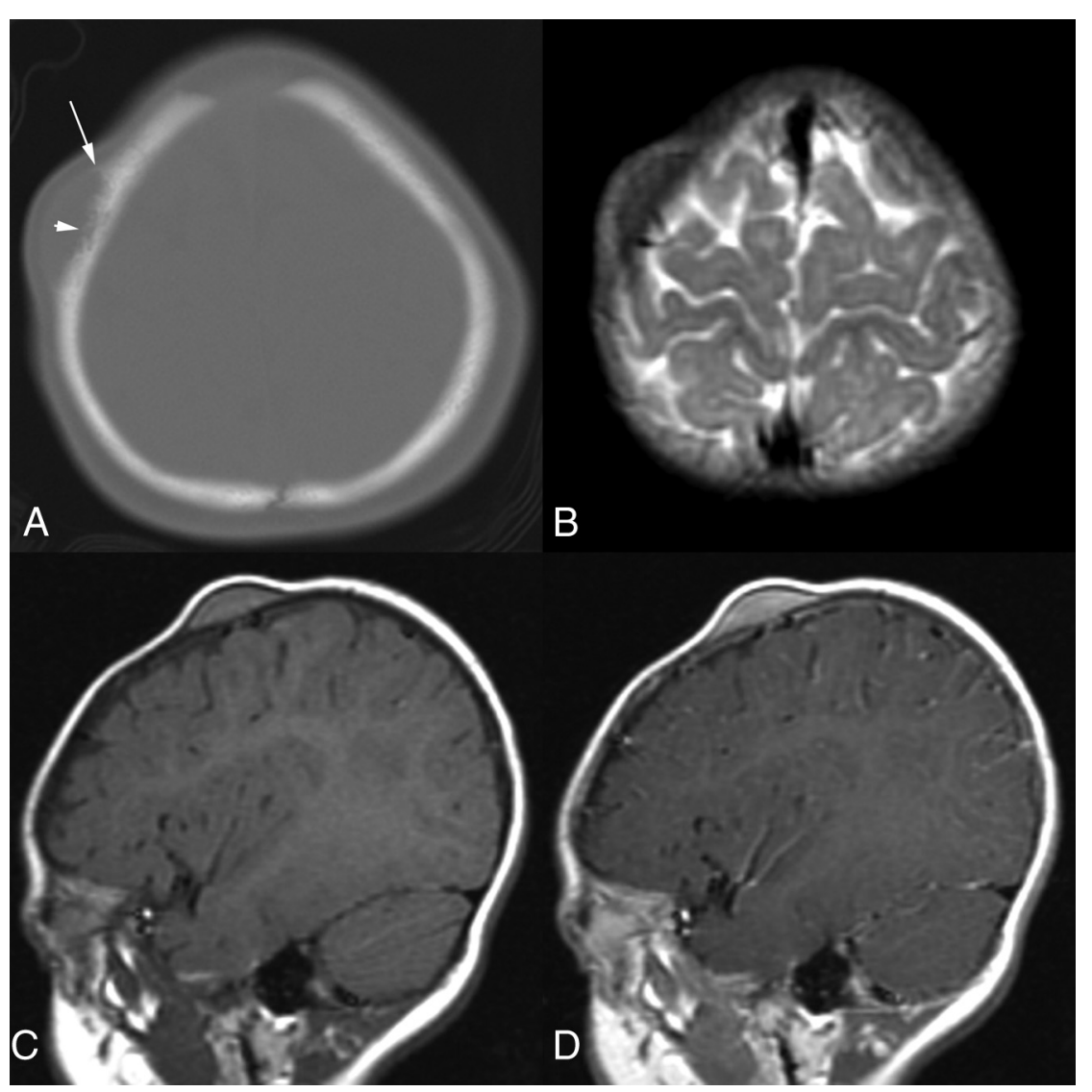

FIG 4. A 7-month-old girl with a 2-week history of a right frontal scalp mass that was clinically thought to represent a dermoid cyst (patient 5). A, Axial CT image shows a semilunar mass with irregular erosion of the calvarial outer table (short arrow) and periosteal reaction (long arrow). $B$, Axial T2-weighted MR image demonstrates that the mass is hypointense relative to the cerebral cortex. C, On this sagittal Tl-weighted MR image, the mass is hyperintense relative to cerebral cortex. D, Sagittal gadolinium-enhanced Tl-weighted MR image shows that the lesion enhances homogeneously. hypoattenuation. Because the examination protocol did not include precontrast imaging, the true determination of enhancement could not be made with certainty.

The MR imaging appearance of JXGs involving the extremities and CNS has been previously described. Intramuscular JXG may have slightly high signal intensity on T2-weighted images and isointense with muscle on T1-weighted images. ${ }^{24}$ Likewise, the MR signal intensity of intracranial and spinal JXG has been reported as similar to that of neural tissue with faint homogeneous enhancement after gadolinium administration. ${ }^{25}$ The higher signal intensity on T1-weighted images compared with the cortex in many of the JXGs in our series is presumably attributable to the presence of lipid within these lesions. Lipidrich zones correspond to xanthomatized areas that are seen histologically, characterized by abundant intracellular fat within histiocytes, and they occur as a variably prominent component of JXG. ${ }^{2}$ The low signal intensity compared with the cortex on T2-weighted images may be attributable to attenuated cellularity, which is a common histologic feature, or collagenous matrix, which is thought to develop with time in JXG. $^{26}$ Decreased diffusivity is also likely attributable to attenuated cellularity and/or collagenous matrix, a feature that simulates higher grade lesions such as neuroblastomas or atypical teratoid/rhabdoid tumors. Ultimately, imaging is useful for delineating the extent of disease and for narrowing the differential diagnosis. ${ }^{17}$

Our review of radiology reports for differential diagnoses provided at the time of imaging highlighted some of the diagnostic pitfalls that can be posed by JXG. The size and location of the JXG

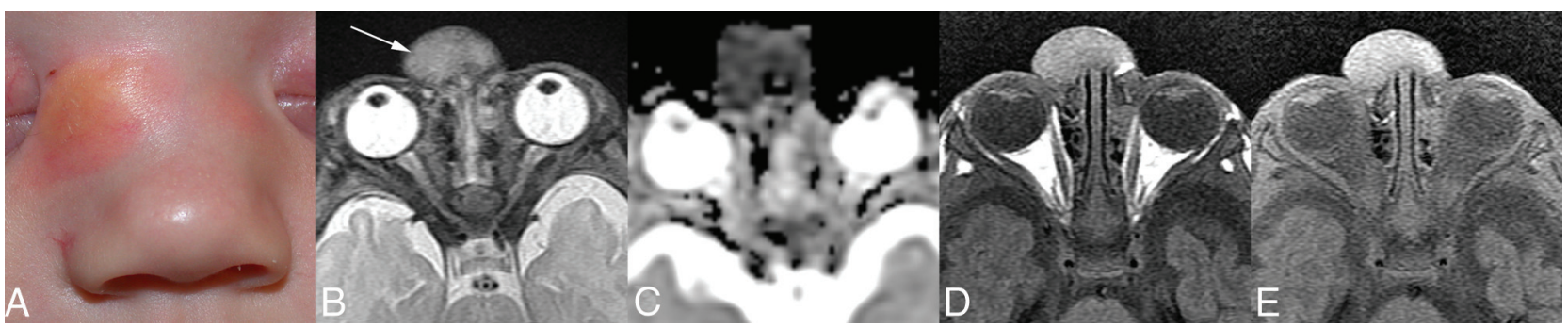

FIG 5. A male infant with a mass over the nose that had been present since birth (patient 7). A, A clinical photograph at 18 days of age demonstrates a raised, yellowish mass with surrounding erythema over the right side of the nasal bridge. Clinically, this was thought to represent a dermoid, neuroglial heterotopia, or cephalocele. B, Axial T2-weighted MR image at 1 month of age demonstrates that the mass (arrow) is isointense with the cerebral cortex with no intracranial connection. C, DWI ADC image shows that the mass has decreased diffusivity compared with the cortex. D, Axial T1-weighted image without contrast demonstrates that the tumor is hyperintense relative to the cortex. $E$, On the gadolinium-enhanced, fat-suppressed T1-weighted image, there is mild homogeneous enhancement, which is difficult to appreciate given the intrinsic hyperintensity on the nonenhanced T1-weighted images. Appreciation of the enhancement is helpful in excluding dermoid and cephalocele. 
affected the radiographic differential diagnosis. For example, the small, nonerosive lesions projecting into the external auditory meatus simulated polyps or dermoids. The cutaneous and subcutaneous infra-auricular lesion was mistaken for a benign tumor of hair follicles or possibly a granulomatous infection. Two cases of midline nasal region JXGs mimicked neuroglial heterotopia, encephalocele, or dermoid/epidermoid on physical examination. One of these lesions was thought to be a neuroglial heterotopia at the time of imaging by virtue of the midline nasofrontal location and similar signal characteristics compared with the cortex. In retrospect, a clue as to the correct diagnosis lay in the relative high signal on T1-weighted imaging before contrast, the relatively low signal intensity on T2, and homogeneous enhancement following the administration of contrast. Three lesions (midline frontal, parietal, and infratemporal fossa eroding temporal bone) that demonstrated bony erosion were originally interpreted at the time of imaging as LCH, metastasis (eg, neuroblastoma), fibrous tumor, or other malignant tumor. Reinterpretation of the imaging for this study revealed intrinsic T1 shortening in 2 of 3 of these lesions

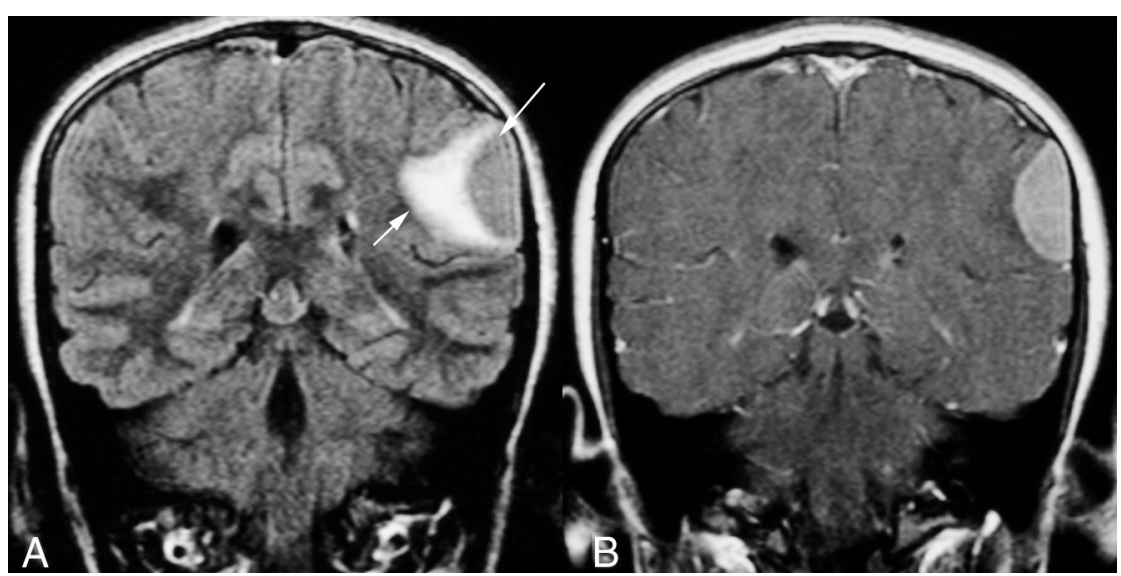

FIG 6. A 12-year-old girl with tremor and recent onset of seizures (patient 9). A, Coronal FLAIR MR image shows confluent hyperintensity due to edema in the brain parenchyma (short arrow) adjacent to the semilunar extra-axial left parietal mass (long arrow), which is isointense with the cortex. B, Contrast-enhanced T1-weighted MR image shows that the extra-axial lesion enhances homogeneously. that again would have been atypical for entities mentioned in the differential diagnosis. Thus, imaging provides information for surgical planning and can be useful in differentiating JXG from other lesions in the clinical differential diagnosis or at least should prompt inclusion of JXG in the differential diagnosis.

Histologic misclassification can be a pitfall in studies requiring histologic-radiologic correlation. In the current study, we believe the histologic diagnoses to have been ascertained with a high level of certainty. When classic histologic features including Touton giant cells are observed, the microscopic findings in JXG are quite distinctive. When Touton giant cells are lacking, the histologic differential may sometimes expand to include other lesions that can show histiocytic differentiation, as can be observed in a subset of inflammatory myofibroblastic tumors and fibrous histiocytomas; however, immunohistologic and sometimes genetic information can be discriminating in these more difficult cases.

Intracranial involvement in JXG is uncommon and, in our limited experience, includes solitary or multiple dural-based lesions and secondary extension from extracranial sites, as demonstrated in the present series. In some cases, there may be parenchymal edema adjacent to the lesions, which can be associated with seizure activity. Multiple intraparenchymal and subarachnoid foci of JXG are rare but are also described in the literature. ${ }^{8}$ Intracranial involvement in JXG is associated with increased mortality and morbidity. ${ }^{8}$ The intracranial lesions tend to grow and require follow-up imaging. ${ }^{11}$ While cutaneous lesions usually resolve spontaneously, extracutaneous lesions may require medical or surgical intervention. ${ }^{8}$ Optimal treatment for unresectable, systemic disease is currently

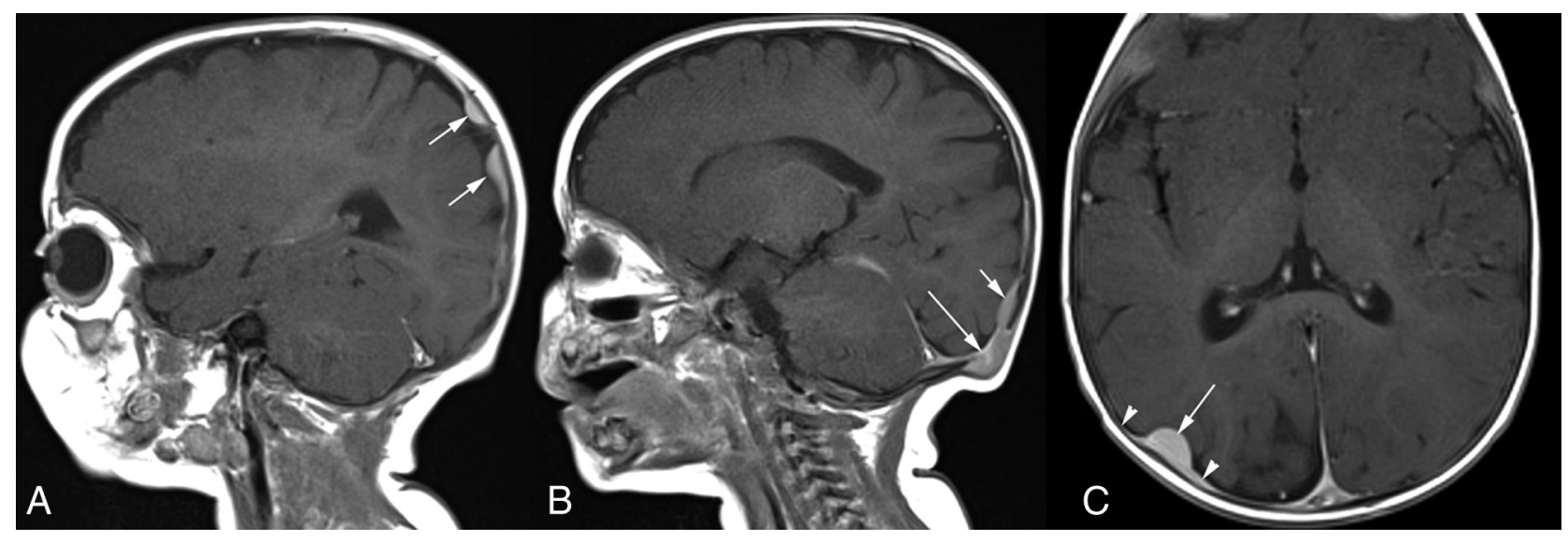

FIG 7. A 9-month-old boy with innumerable skin lesions, visceral lesions, and a diagnosis of disseminated JXG (patient 10). A, Sagittal contrastenhanced T1-weighted MR image shows homogeneously enhancing, lobulated, parietal dural-based enhancing lesions (arrows). B, More medially, there is an erosive lesion within the occipital bone (long arrow) with contiguous plaquelike dural enhancement superiorly (short arrow). $C$, Axial contrast-enhanced T1-weighted MR image shows a homogeneously enhancing, dome-shaped dural-based lesion (long arrow) with tapered dural thickening and enhancement (arrowheads), also known as a "dural tail." 
undefined; however, treatment regimens similar to those used for LCH have been used successfully. ${ }^{27-29}$

\section{CONCLUSIONS}

JXG of the HN has a variety of manifestations and can simulate $\mathrm{LCH}$, fibrous tumors, and high-grade, highly cellular lesions such as neuroblastoma or other malignant neoplasms. The presence of a soft-tissue mass with intrinsically high signal intensity on T1weighted images and relatively low signal intensity on T2weighted MR images relative to the cerebral cortex, homogeneous enhancement, and decreased diffusivity may suggest the diagnosis of JXG. Familiarity with the common locations, typical imaging appearances, and recognized diagnostic pitfalls outlined herein may prompt radiologists to include JXG in the radiographic differential diagnosis for head and neck masses.

Disclosures: Sara O. Vargas_UNRELATED: Expert Testimony: Previous testimony as an expert witness for medical malpractice cases. Medical issues involved were unrelated to the topic of the current work.

\section{REFERENCES}

1. Jaffe R, Fletcher CD, Burgdorf WH. Disseminated juvenile xanthogranuloma. In: Swerdlow SH, Campo E, Harris NL, et al, eds. WHO Classification of Tumours of Haematopoietic and Lymphoid Tissues. 4th ed. Lyon: IARC; 2008:366-67

2. Dehner LP. Juvenile xanthogranulomas in the first two decades of life: a clinicopathologic study of 174 cases with cutaneous and extracutaneous manifestations. Am J Surg Pathol 2003;27:579-93 CrossRef Medline

3. Konar S, Pandey P, Yasha TC. Solitary juvenile xanthogranuloma in cervical spine: case report and review of the literature. Turk Neurosurg 2014;24:102-07 CrossRef Medline

4. Baik FM, Andeen NK, Schmechel SC, et al. A large juvenile xanthogranuloma within the tongue. Otolaryngol Head Neck Surg 2014; 150:332-33 CrossRef Medline

5. Puerta $P$, Candela S, Rovira C, et al. Juvenile xanthogranuloma of skull base: case report and review of the literature. Acta Neurochir (Wien) 2013;155:1039-40 CrossRef Medline

6. Chiba K, Aihara Y, Eguchi S, et al. Diagnostic and management difficulties in a case of multiple intracranial juvenile xanthogranuloma. Childs Nerv Syst 2013;29:1039-45 CrossRef Medline

7. Chu MW, Werner A, Moody-Antonio SA. Juvenile xanthogranuloma of the tympanic membrane: a case report. Ear Nose Throat J 2012;91:364, 366, 368 Medline

8. Lalitha P, Reddy MCh, Reddy KJ. Extensive intracranial juvenile xanthogranulomas. AJNR Am J Neuroradiol 2011;32:E132-33 CrossRef Medline

9. Johnson TE, Alabiad C, Wei L, et al. Extensive juvenile xanthogranuloma involving the orbit, sinuses, brain, and subtemporal fossa in a newborn. Ophthal Plast Reconstr Surg 2010; 26:133-34 CrossRef Medline

10. Sun LP, Jin HM, Yang B, et al. Intracranial solitary juvenile xanthogranuloma in an infant. World J Pediatr 2009;5:71-73 CrossRef Medline

11. Kasliwal MK, Suri A, Rishi A, et al. Symptomatic bilateral cerebellar mass lesions: an unusual presentation of intracranial xanthogranuloma. J Clin Neurosci 2008;15:1401-04 CrossRef Medline

12. Cao D, Ma J, Yang X, et al. Solitary juvenile xanthogranuloma in the upper cervical spine: case report and review of the literatures. Eur Spine J 2008;17(suppl 2):S318-23 Medline

13. Margulis A, Melin-Aldana H, Bauer BS. Juvenile xanthogranuloma invading the muscles in the head and neck: clinicopathological case report. Ann Plast Surg 2003;50:425-28 CrossRef Medline

14. Behne K, Casey T. Ulcerated juvenile xanthogranuloma of the scalp. Australas J Dermatol 2003;44:74-75 CrossRef Medline

15. Thevasagayam MS, Ghosh S, O'Neill D, et al. Isolated juvenile xanthogranuloma of the subglottis: case report. Head Neck 2001;23 426-29 CrossRef Medline

16. Saravanappa N, Rashid AM, Thebe PR, et al. Juvenile xanthogranuloma of the nasal cavity. J Laryngol Otol 2000;114:460-61 Medline

17. Miszkiel KA, Sohaib SA, Rose GE, et al. Radiological and clinicopathological features of orbital xanthogranuloma. $\mathrm{Br} J$ Ophthalmol 2000;84:251-58 CrossRef Medline

18. Shapiro NL, Malis DJ, Charon CC, et al. Giant juvenile xanthogranuloma of the tongue. Am J Otolaryngol 1999;20:241-44 CrossRef Medline

19. Hidayat AA, Mafee MF, Laver NV, et al. Langerhans' cell histiocytosis and juvenile xanthogranuloma of the orbit: clinicopathologic, CT, and MR imaging features. Radiol Clin North Am 1998;36:1229_ 40, xii Medline

20. Tamir I, Davir R, Fellig Y, et al. Solitary juvenile xanthogranuloma mimicking intracranial tumor in children. J Clin Neurosci 2013;20: 183-88 CrossRef Medline

21. Deisch JK, Patel R, Koral K, et al. Juvenile xanthogranulomas of the nervous system: a report of two cases and review of the literature. Neuropathology 2013;33:39-46 CrossRef Medline

22. Cornips EM, Cox KE, Creytens DH, et al. Solitary juvenile xanthogranuloma of the temporal muscle and bone penetrating the dura mater in a 2-month-old boy. J Neurosurg Pediatr 2009;4:588-91 CrossRef Medline

23. Yeh BM, Nobrega KT, Reddy GP, et al. Juvenile xanthogranuloma of the heart and liver: MRI, sonographic, and CT appearance. $A J R$ Am J Roentgenol 2007;189:W202-04 CrossRef Medline

24. David JK, Anupindi SA, Deshpande V, et al. Intramuscular juvenile xanthogranuloma: sonographic and MR findings. Pediatr Radiol 2003;33:203-06 CrossRef Medline

25. Rampini PM, Alimehmeti RH, Egidi MG, et al. Isolated cervical juvenile xanthogranuloma in childhood. Spine (Phila Pa 1976) 2001; 26:1392-95 CrossRef Medline

26. Patterson JW, Wick MR. Nonmelanocytic Tumors of the Skin: AFIP Atlas of Tumor Pathology. Washington: American Registry of Pathology; 2006:389-413

27. Auvin S, Cuvellier JC, Vinchon M, et al. Subdural effusion in a CNS involvement of systemic juvenile xanthogranuloma: a case report treated with vinblastin. Brain Dev 2008;30:164-68 Medline

28. Nakatani T, Morimoto A, Kato R, et al. Successful treatment of congenital systemic juvenile xanthogranuloma with Langerhans cell histiocytosis-based chemotherapy. J Pediatr Hematol Oncol 2004;26: 371-74 Medline

29. Simko SJ, Tran HD, Jones J, et al. Clofarabine salvage therapy in refractory multifocal histiocytic disorders, including Langerhans cell histiocytosis, juvenile xanthogranuloma and Rosai-Dorfman disease. Pediatr Blood Cancer 2014;61:479-87 CrossRef Medline 